\title{
The effects of UV radiation on photosynthesis estimated as chlorophyll fluorescence in Zygnemopsis decussata (Chlorophyta) growing in a high mountain lake (Sierra Nevada, Southern Spain)
}

\author{
Félix L. FIGUEROA*, Nathalie KORBEE, Presentación CARRILLO ${ }^{1)}$, Juan Manuel MEDINA-SÁNCHEZ ${ }^{1)}$, \\ Mayte MATA, Jose BONOMI ${ }^{2}$ and Pedro M. SÁNCHEZ-CASTILLO ${ }^{3)}$ \\ Departamento de Ecología y Geología, Facultad de Ciencias, Universidad de Málaga, 29071, Málaga, Spain \\ ${ }^{1)}$ Departamento de Ecología, Facultad de Ciencias, Universidad de Granada, 18071 Granada, Spain \\ ${ }^{2)}$ Departamento de Botânica, Instituto de Biociências da Universidade de São Paulo Rua do Matão, 277 Caixa Postal 11461 Cidade \\ Universitária, 05422-970 São Paulo, Brasil \\ ${ }^{3)}$ Departamento de Biologia Vegetal, Facultad de Ciencias, Universidad de Granada, 18071 Granada, Spain \\ *e-mail corresponding author: felix_lopez@uma.es
}

\begin{abstract}
The effect of increased UV radiation on photosynthesis estimated as in vivo chlorophyll fluorescence i.e. optimal quantum yield $\left(\mathrm{F}_{\mathrm{v}} / \mathrm{F}_{\mathrm{m}}\right)$ and electron transport rate (ETR) in the green filamentous alga Zygnemopsis decussata (Streptophyta, Zygnematales) growing in the high mountain lake "La Caldera" (Sierra Nevada, Spain) at $3050 \mathrm{~m}$ altitude was evaluated. Two sets of in situ experiments were conducted: (1) On July 2006, $\mathrm{F}_{\mathrm{v}} / \mathrm{F}_{\mathrm{m}}$ was measured throughout the day at different depths $(0.1,0.25,0.5$ and $1 \mathrm{~m})$ and in the afternoon, ETR and phenolic compounds were determined. In addition, in order to analyze the effect of $U V$ radiation, $\mathrm{F}_{\mathrm{v}} / \mathrm{F}_{\mathrm{m}}$ was determined in algae incubated for 3 days at $0.5 \mathrm{~m}$ under three different light treatments: $P A R+U V A+U V B(P A B)$, $P A R+U V A$ (PA) and PAR (P). (2) On August 2007, $\mathrm{F}_{\mathrm{v}} / \mathrm{F}_{\mathrm{m}}$ was determined under PAB, $P A$ and $P$ treatments and desiccation/rehydration conditions. $\mathrm{F}_{\mathrm{v}} / \mathrm{F}_{\mathrm{m}}$ decreased in algae growing in surface waters $(0.1 \mathrm{~m})$ but also at $1 \mathrm{~m}$ depth compared to that at $0.5 \mathrm{~m}$ depth. The decrease of $\mathrm{F}_{\mathrm{v}} / \mathrm{F}_{\mathrm{m}}$ at noon due to photoinhibition was small (less than $10 \%$ ) except in algae growing at $1 \mathrm{~m}$ depth (44\%). The maximal electron transport rate was 3.5-5 times higher in algae growing at 0.25-0.5 $\mathrm{m}$ respectively than that at 0.1 and $1 \mathrm{~m}$ depth. These results are related to the accumulation of phenolic compounds: i.e. the algae at 0.25-0.5 $\mathrm{m}$ presented respectively about a 3-5 times higher concentration of phenolic compounds than that of algae at 0.1-1 $\mathrm{m}$ depth. The protection mechanisms seem to be stimulated by UVB radiation, since $\mathrm{F}_{\mathrm{v}} / \mathrm{F}_{\mathrm{m}}$ was higher in the presence of UVB (PAB treatment) compared to $P A$ or P treatments. UVA exerts the main photoinhibitory effect, not only at midday, but also in the afternoon. UVB radiation also had a protective effect in algae grown under desiccation conditions for three days. During re-hydration, the rapid increase of $\mathrm{F}_{\mathrm{v}} / \mathrm{F}_{m}$ (after $1 \mathrm{~h}$ ) was higher in the UVB-grown algae than in algae grown under UVA radiation. After 5 h, $\mathrm{F}_{\mathrm{v}} / \mathrm{F}_{\mathrm{m}}$ values were similar in algae submitted to desiccation/rehydration under PAB and P treatments as they were in the control (submerged algae). The combined effect of desiccation and UVA produced the greatest decrease of photosynthesis in Z. decussata. Thus UVB, in contrast to other species, may support the recovery process. Z. decussata can acclimate to severe stress conditions in this high mountain lake by the photoprotection mechanism induced by UVB radiation through dynamic photoinhibition and the accumulation of phenolic compounds (UV screen and antioxidant substances).
\end{abstract}

Key words: chlorophyll fluorescence, high mountain lake, phenols, photosynthesis, UV radiation, Zygnemopsis decussata

\section{INTRODUCTION}

Increased UVB radiation at the Earth's surface due to stratospheric ozone depletion (Shindell et al. 1998) and low-ozone events in Europe (Pérez et al. 2002; Keil et al. 2007) can negatively impact the structure-function of aquatic ecosystems (Franklin \& Forster 1997; Bischof et al. 2006) and processes from molecular to ecophysiological scales, i.e. DNA synthesis, biochemical composition, photosynthesis (Day \& Neale 2002), nutrient uptake (Hessen et al. 1997), biomass, species composition, and growth rates in phytoplankton and peryphyton (Vinebrooke \& Leavitt 1996; Buma et al. 2003; Leu et al. 2007).

Although the concentration of ozone-depleting substances in the atmosphere is decreasing, the ozone layer is still far from recovering its values of the eighties. There is greater uncertainly about future UVB radiation than future ozone concentrations, as UVB radiation will be additionally influenced by climate change (McKenzie et al. 2007). At some sites in the Northern Hemisphere, UVB irradiance may continue to increase because of continuing reduction in aerosol extinction since 1990. The ozone layer is not expected to recover until 2070 due to the decrease of the temperature in the stratosphere as an effect of climate change (Caldwell et al. 2007). The decrease of the ozone layer in the south of the Iberian Peninsula has been about $0.3 \%$ per year, corresponding to a $0.5-0.75 \%$ increase in biological weighted irradiance related to DNA damage and algal photoinhibition (Häder et al. 2007).

UVB radiation is naturally greater in high mountain lakes, due both to altitude (UVB increasing about 8- 
$10 \%$ every $1000 \mathrm{~m}$ ) and to the low level of aerosols (McKenzie et al. 2007). The effect of UV radiation on phytoplankton and trophic relationships has been intensively studied in high mountain lakes (Sommaruga 2001; Carrillo et al. 2002, 2008), whereas most studies on the effects of UV radiation on benthic communities in high mountain or high latitude lakes have been conducted on epilithic phytobenthos (Vinebrooke \& Leavitt 1996; Tank et al. 2003; Weidman et al. 2005). A few studies have been conducted on filamentous algae. Weidman et al. (2005) reported that filamentous chlorophytes and cyanophytes are the dominant algae in oligotrophic boreal lakes at $0.5 \mathrm{~m}$ and $1.4 \mathrm{~m}$ depth respectively, and are not affected by UVB radiation.

Filamentous green algae are expected to have photoprotection mechanisms against UV solar radiation, as they are fixed on stones or sediments and are exposed to very high UV radiation on account of the altitude and the high penetration of UV radiation (Carrillo et al. 2002, 2008). Algae can present UV screen substances such as mycosporine-like amino acids (Korbee et al. 2006) and phenolic compounds (Pérez-Rodríguez et al. 2001; Connan et al. 2004; Han \& Han 2005; Abdala et al. 2006). Choo et al. (2005) reported that carotenoids in green filamentous algae provided effective protection against increased oxidative stress due to UVB radiation. In our study, phenolic compounds were determined as possible indicators of acclimation to increased UV radiation.

Another bioindicator of the physiological status of algae under increased UV radiation is in vivo chlorophyll fluorescence: maximal quantum yield and electron transport rate have been used as indicators in algae from both marine (Figueroa et al. 1997, 2003) and continental waters (Arróniz-Crespo et al. 2006; Conde-Álvarez et al. 2008). Dynamic photoinhibition as a mechanism of acclimation to increased photosynthetic irradiance can be estimated as chlorophyll fluorescence (Figueroa et al. 2003; Bischof et al. 2006).

In this paper, the effect of the in situ UV radiation on photosynthesis, estimated as chlorophyll fluorescence of Zygnemopsis decussata growing in a high mountain lake (La Caldera, 3050 m.a.s.l.), was analyzed comparing full solar exposure (PAR+UVA+UVB treatment) with exposures cutting off UVB radiation (PAR+UVA treatment) and cutting off both UVA and UVB radiations (PAR treatment). Photosynthesis was also determined under naturally decreasing UV radiation, i.e. chlorophyll fluorescence in algae growing at different depths. The combined effect of solar UV radiation and desiccation/hydration on photosynthesis was also evaluated.

The recent development of beds of filamentous algae on the littoral area of La Caldera lake (Carrillo et al. 2008) prompted us to evaluate their ecophysiological response to the two important stressors on this ecosystem, UVR and the fluctuating level of the lake water.
Due to its location in a glacial cirque above the tree-line and the absence of visible inlets or outlets, La Caldera is highly sensitive to any significant variation in the precipitation regime (Villar-Argaiz et al. 2001; SánchezCastillo et al. 2008).

\section{METHODS}

\subsection{Site description}

The study was conducted in La Caldera lake, a remote high-mountain lake situated above the tree-line (3050 m a.s.l.), in the Sierra Nevada National Park (Southern Spain, $36^{\circ} 55^{\prime}-37^{\circ} 15^{\prime} \mathrm{N}, 2^{\circ} 31^{\prime}-3^{\circ} 40^{\prime} \mathrm{W}$ ). The lake water is highly transparent (Secchi disk visibility reaching the maximum depth) and dissolved organic carbon (DOC) concentration is below $1 \mathrm{mg} \mathrm{L}^{-1}$ (Reche et al. 2001). $\mathrm{N}: \mathrm{P}$ ratio values are $>180$ and dissolved inorganic nitrogen (DIC):P mass ratio values are $>40$, indicating a strong $\mathrm{P}$ limitation (Villar-Argaiz et al. 2001; Carrillo et al. 2008).

\subsection{Physical variables}

Average spectral irradiance in the air was determined by using a multidiode spectroradiometer model SMS-500, scanning every $1 \mathrm{~nm}$ from 280 to $700 \mathrm{~nm}$ (Sphereoptics LLC, Concord, NH). Three measurements were conducted each day around noon (14:00 local time) on 17 and 20 July 2006 and on 20 and 23 August 2007. The irradiance of PAR, expressed as $\mu \mathrm{mol} \mathrm{m}^{-2} \mathrm{~s}^{-1}$, was determined from the whole spectrum integrating each $1 \mathrm{~nm}$ from 400-700 $\mathrm{nm}$, whereas UVA and UVB irradiances, expressed as $\mathrm{W} \mathrm{m}^{-2}$, were determined by integration from 315 to $400 \mathrm{~nm}$ and from 280 to $315 \mathrm{~nm}$ respectively.

Underwater irradiance-depth profiles were obtained on sunny days on 17 and 20 July 2006 and on 20 and 23 August 2007 (within $3 \mathrm{~h}$ of solar noon), for 305, 320, $380 \mathrm{~nm}$ and PAR $(400-700 \mathrm{~nm})$ using a multichannel radiometer (BIC-2104 P, Biospherical Instrument, Inc.). Diffuse attenuation coefficients for downward irradiance $\left(K_{d}\right)$ were determined from the slope of the linear regression of the natural logarithm of downwelling irradiance $(E)$ versus depth $(z)$. A large sample size (pairs of $E$ and $z$ values, $n>100$ ) was used and a good fit $\left(r^{2}>0.9\right)$ was obtained for all regressions. Logarithmic dependencies of light attenuation on water depths were calculated by non-linear regression over a depth profile of several meters. Optical stratification of the water body is visible if the data deviate from its logarithmic regularity. $K_{d}$ values were calculated for the whole PAR range and for three cited UV wavelengths.

\subsection{Filamentous algae}

Zygnemopsis decussata (Transeau) is a filamentous green alga (Streptophyta, Zygnematales) of primitive thaloid organization with cells arranged in single uniseriate filaments. Cells are cylindrical with two stellate 
chloroplasts bearing a central pyrenoid. The Zygnemopsis species presents two types of reproduction, one asexual by means of akinetes (thickened wall cells with condensed cytoplasm) and the other sexual by gametangial copulation with scaleriform (ladder-like) joining. In common with other zygnematals, this species forms dense populations that cover the edges of lakes in green slimy masses.

\subsection{In situ experiment: effect of $P A R$ and UVR on photosynthesis (July 2006)}

A number of experiments were conducted in July 2006 (16-20 July 2006):

1) Effect of increasing depth: 8 different thalli (green slimy masses) at four different depths $(0.1,0.25,0.5$ and $1 \mathrm{~m}$ ) were marked with lines. Samples were collected on 17 July 2006 at different times during the day $(11: 30,14: 30$ and 17:30 h) and kept for 15 min in darkness to determine optimal quantum yield. In the afternoon, samples to determine electron transport rate were also taken. The data in the figures are expressed as average \pm standard deviation from 8 replicates.

2) Effect of UVA and UVB radiation: In order to analyze the effect of UVB (280-315 nm) and UVA $(315-400 \mathrm{~nm})$ radiation on photosynthesis, algae were incubated in situ under different light treatments. A frame with UV cut-off filters was located on algae (distance $10 \mathrm{~cm}$ ) growing at $0.5 \mathrm{~m}$ depth. Three different cut-off filters were used to provide the following light conditions: a) PAR + UVA + UVB (PAB treatment), by use of Ultraphan 295 (Digefra GmbH, Munich, Germany) b) PAR + UVA (PA treatment), by use of Folex 320 (Folex GmbH, Dreieich, Germany) c) PAR alone (P treatment), by use of Ultraphan 395 (Digefra GmbH, Munich, Germany). The spectral characteristics of the UV cut-off filters have been reported previously (Figueroa et al. 1997; Villafañe et al. 2003).

The algae were incubated in the above-described conditions for three days (from 17 to 20 July 2006). Optimal quantum yield was determined in algae collected at 14:00 h, 16:00 $\mathrm{h}$ and 18:00 h local time and after incubation for $15 \mathrm{~min}$ in darkness. The data in the figures are expressed as average \pm standard deviation from 8 replicates.

This experimental design presents various advantages: firstly, the exposure to natural ratios of PAR to UV radiation, which is difficult to achieve using artificial sources and permits a more realistic extrapolation to the situation in the field; secondly, it is possible to standardise conditions for algal growth, a situation normally not found in natural habitats, where an unpredictable environment (e.g., water motion or heterogeneous light exposure) makes in situ experimentation difficult. Finally, the permanent availability of algae permits exhaustive monitoring of the physiological responses at different time intervals throughout the day.

\subsection{In situ experiment: combined effect of UV radiation and desiccation}

In August 2007, the lake contained a much lower volume of water than in July 2006. We had intended to repeat the 2006 experiment, but due to the changed situation, only a few specimens of $Z$. decussata were found at $0-0.2 \mathrm{~m}$ depth. As in the July 2006 experiment, a frame with the different UV cut-off filters was located on algae growing in situ (P, PA and PAB treatments). The incubation lasted three days, from 20 to 23 August 2007. After this period, due to the drastic loss of water from the lake, the algae were found under emersion conditions but were only partially desiccated. Optimal quantum yield (at 14:00 h local time) was determined after $15 \mathrm{~min}$ in darkness. The algae were then transferred to water to be completely rehydrated under low solar irradiance conditions using neutral filters, for $1 \mathrm{~h}$ at about $200-300 \mu \mathrm{mol} \mathrm{m}^{-2} \mathrm{~s}^{-1}$ (a treatment called $3 \mathrm{~d}+1 \mathrm{~h}$ $\mathrm{H}$ ) and $5 \mathrm{~h}$ at about $100-200 \mu \mathrm{mol} \mathrm{m} \mathrm{s}^{-2}$ (a treatment called $3 \mathrm{~d}+5 \mathrm{~h} \mathrm{H})$. A fully hydrated plant collected in situ from shallow-waters $(0.1 \mathrm{~m}$ depth) was used as control. The data in the figures are expressed as average \pm standard deviation from 8 replicates.

\subsection{Chlorophyll fluorescence}

In vivo chlorophyll fluorescence of PSII was determined with two portable pulse modulation fluorometers (Diving-PAM and Water-PAM, Walz GmbH, Effeltrich, Germany). Algae were collected from each depth during the day, and after being kept in darkness for $15 \min F_{o}$ and $F_{m}$ were determined by using a Diving-PAM to obtain the maximal quantum yield of fluorescence $\left(F_{\vee} / F_{m}\right)$ (Schreiber et al. 1995). The saturating pulse was of $800 \mathrm{~ms}$ and irradiance of about $6000 \mu \mathrm{mol} \mathrm{m} \mathrm{m}^{-2} \mathrm{~s}^{-1}$. The variable fluorescence $F_{v}$ is the difference between the maximal fluorescence from fully reduced PSII reaction center $\left(F_{m}\right)$ and the intrinsic fluorescence $\left(F_{o}\right)$ from the antenna of fully oxidized PSII.

The effective quantum yield $\left(\Delta F / F_{m}^{\prime}\right)$ was determined by using a Water-PAM fluorometer in algae collected from each depth and after 15 exposure at different intensities of red light by using the red light-emitted diodes of the Water-PAM $(158,230,350,520,737$, 1017,1642 and $2369 \mu \mathrm{mol}$ photons $\left.\mathrm{m}^{-2} \mathrm{~s}^{-1}\right) . \Delta F / F^{\prime}{ }_{m}$ was calculated according to Schreiber et al. (1995):

$$
\Delta F / F^{\prime}{ }_{m}=\left(F_{m}^{\prime}-F_{t}\right) / F_{m}^{\prime}
$$

where $F_{m}^{\prime}$ is the maximal fluorescence induced with a saturating white light pulse and $F_{t}$ the current steady-state fluorescence in light-adapted algae. The saturating pulse was of $800 \mathrm{~ms}$ and irradiance of about $6000 \mu \mathrm{mol} \mathrm{m}^{-2} \mathrm{~s}^{-1}$.

The electron transport rate (ETR) as rapid light curves was determined after 15 exposure to the eight incremental irradiances of red light indicated above, following the formula reported by Schreiber et al. (1995): 
ETR $\left(\mu \mathrm{mol}\right.$ electrons $\left.\mathrm{m}^{-2} \mathrm{~s}^{-1}\right)=\Delta F / F_{m}^{\prime} \times A Q_{\lambda} \times F_{I I}$

where $A Q_{\lambda}$ is the absorbed quanta calculated as the product of the integration of the spectral absorptance $(A)$ between $400-700 \mathrm{~nm}$ and the spectral irradiance of the light source $\left(E_{\lambda}\right)$. The absorptance $(A)$ was estimated by using a cosine-corrected PAR sensor (Licor $192 \mathrm{SB}$ ) according to Figueroa et al. (2003). The procedure consists in determining PAR under solar radiation $\left(E_{o}\right)$ and with the algae located on the PAR sensor $\left(E_{t}\right)$. The absorptance is calculated as $A=1-E_{t} / E_{o}$. The reflectance is not determined and is generally lower than $10 \%$ of the $E_{o}$ (Figueroa et al. 2003), $F_{I I}$ is the fraction of $A Q$ directed to PSII including its light harvesting complexes (LHCs) and $\Delta F / F^{\prime}{ }_{m}$ is the effective quantum yield or quantum yield of PSII charge separation as was defined above. According to Grzymski et al. (1997), $F_{I I}$ for different pigment groups can be estimated by determining the fraction of Chl- $a$ associated with PSII and its corresponding light-harvesting complexes, i.e. LHCII. $F_{I I}$ is about 0.5 for Chlorophyta (Grzymski et al. 1997; Figueroa et al. 2003). Two replicates (two different specimens) of rapid light curves per depth were conducted.

The initial slope $(\alpha)$ of the ETR-E function was calculated from the first 5 intensities $(158,230,350,520$ and $737 \mu \mathrm{mol}$ photons $\mathrm{m}^{-2} \mathrm{~s}^{-1}$ ) and maximal ETR (ETR max) according to tangential function modified from Jassby \& Platt (1976):

$$
\mathrm{ETR}=\mathrm{ETR}_{\text {max }} \cdot \tanh \left(\frac{\alpha \mathrm{E}}{\mathrm{ETR}_{\text {max }}}\right)
$$

\subsection{Phenolic compounds}

The phenol concentration was evaluated by using $0.25 \mathrm{~g}$ wet weight in six different algae $(\mathrm{n}=6)$. Samples were collected in the afternoon on 17 July 2006 (experiment on the effect of depth on photosynthesis) at different depths $(0.1,0.25,0.5$ and $1 \mathrm{~m})$. They were transported from the lake to the laboratory in cold water $\left(4{ }^{\circ} \mathrm{C}\right)$ and stored at $-80{ }^{\circ} \mathrm{C}$ before extraction and analysis. Samples were pulverized in a mortar and pestle in liquid nitrogen, and extracted overnight in centrifuge tubes with $2.5 \mathrm{ml}$ of $80 \%(\mathrm{v} / \mathrm{v})$ methanol. The mixture was centrifuged at $19000 \mathrm{~g}$ for $15 \mathrm{~min}$ and the supernatant was collected. Total phenolic compounds were determined colorimetrically using Folin-Ciocalteu assay (Folin \& Ciocalteu 1927). Phloroglucinol (1,3,5-trihydroxybenzene, Sigma P-3502) was used as standard. Phenolic concentration was expressed as $\mathrm{mg} \mathrm{g}^{-1}$ d.w. after determining the wet to dry ratio in the tissue. The data in the figures are expressed as average \pm standard deviation from 6 replicates.

\subsection{Statistical analysis}

The statistical differences among treatments were tested by means of two-way ANOVA (model I). Using the least significant difference of Fisher multi-range test
(LSD), means were compared according to Sokal \& Rohlf (1995). Significances were always at $p<0.05$.

\section{RESULTS}

The average solar irradiance in the air during the experimental time reached high values at $14: 00 \mathrm{~h}$ local time (12:00 GMT) i.e. $1.88 \mathrm{~W} \mathrm{~m}^{-2}$ of UVB, $47.56 \mathrm{~W} \mathrm{~m}^{-2}$ of UVA and $1670 \mu \mathrm{mol} \mathrm{m}{ }^{-2} \mathrm{~s}^{-1}$ of PAR on July 2006, and $1.70 \mathrm{~W} \mathrm{~m}^{-2}$ of UVB, $42.71 \mathrm{~W} \mathrm{~m}^{-2}$ of UVA and 1491 $\mu \mathrm{mol} \mathrm{m} \mathrm{s}^{-1}$ of PAR on August 2007 (Fig. 1).

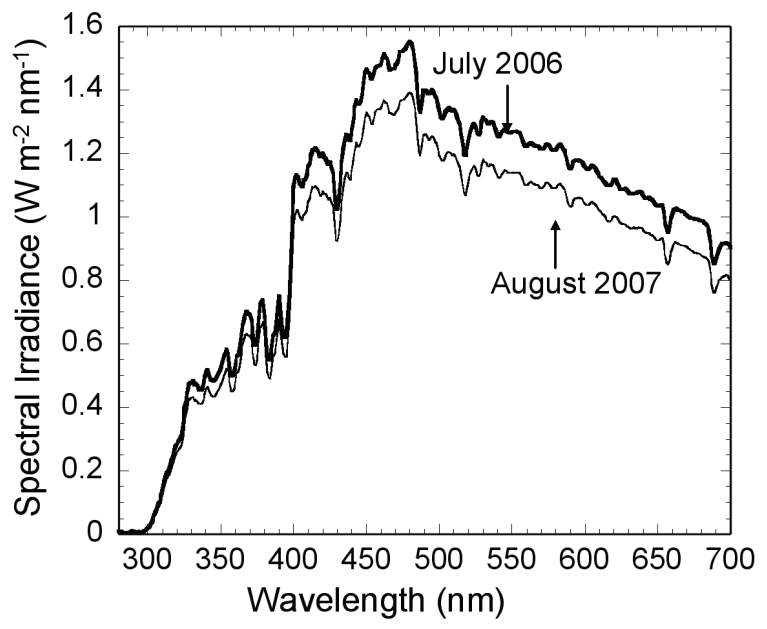

Fig. 1. Average spectral irradiance in the air expressed in $\mathrm{W}$ $\mathrm{m}^{-2} \mathrm{~nm}^{-1}$ from 300 to $700 \mathrm{~nm}$ by using a multidiode spectroradiometer (Sphere Optics, SMS 500). The spectra represents the average of three measurements conducted each day around noon (14:00 h local time) on 17 and 20 July 2006 and on 20 and 23 August 2007.

The irradiance of underwater UV radiation (at 305, 320 and $380 \mathrm{~nm}$ ) and PAR versus depth is represented in figure 2. In July 2006 the measurements were conducted to about $5.5 \mathrm{~m}$ depth, but in August 2007 only to about $2 \mathrm{~m}$ depth, due to the drastically different water volume in the lake during the two sampling periods. The attenuation coefficient of downward radiation was higher in July 2006 than in August 2007 for UV radiation, while the reverse was observed in the case of PAR (Tab. 1).

Tab. 1. Average \pm standard deviation of the attenuation coefficients of the downward radiation $\left(K_{d}\right.$, expressed as $\mathrm{m}^{-1}$ ) of UV radiation at 305,320 and 380 $\mathrm{nm}$ and of PAR (400-700 nm) determined during the experimental time (July 2006 and August 2007) in La Caldera lake at different times from 13:00 h to 16:00 h local time.

\begin{tabular}{ccc}
\hline Wavelength $(\mathrm{nm})$ & July 2006 & August 2007 \\
\hline 305 & $1.15 \pm 0.10$ & $0.90 \pm 0.06$ \\
320 & $1.02 \pm 0.09$ & $0.75 \pm 0.04$ \\
380 & $0.66 \pm 0.04$ & $0.51 \pm 0.03$ \\
$400-700$ & $0.38 \pm 0.03$ & $0.47 \pm 0.03$ \\
\hline
\end{tabular}




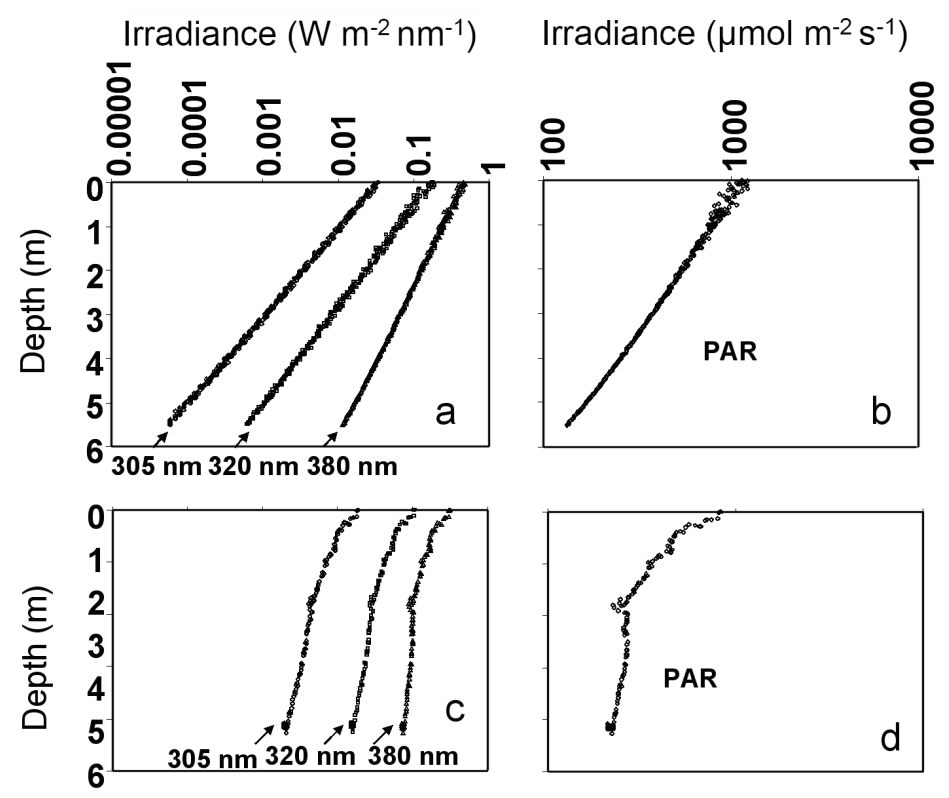

Fig. 2. Average irradiance-depth profiles obtained on sunny days on 17 and 20 July 2006 (a, b) and 20 and 23 August 2007 (c, d), within $3 \mathrm{~h}$ of solar noon, for 305, 320, $380 \mathrm{~nm}(\mathbf{a}, \mathbf{c})$ and PAR (400-700 nm) (b, d) using a multichannel radiometer (BIC-2104 P, Biospherical Instrument, Inc.).

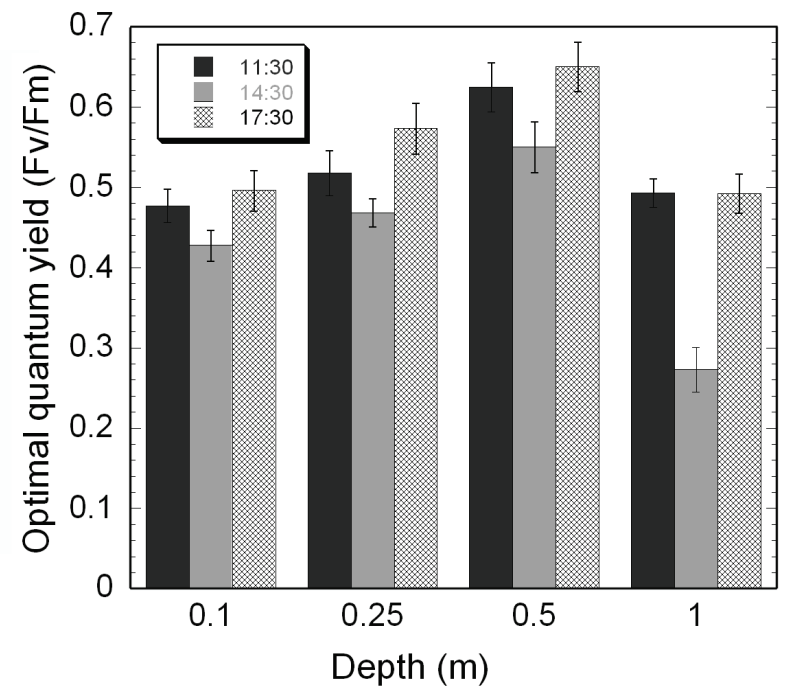

Fig. 3. Optimal quantum yield $\left(F_{v} / F_{m}\right)$ of Zygnemopsis decussata growing at different depths $(0.1,0.25,0.5$ and $1 \mathrm{~m})$. The measurements were conducted on 17 July 2006 at different times throughout the day $(11: 30,14: 30$ and 17:30 h local time). Data are expressed as mean value $\pm \operatorname{SD}(n=8)$.

The optimal quantum yield $\left(F_{v} / F_{m}\right)$ was followed throughout the day (17 July 2006) in situ in filamentous algae growing at different depths (Fig. 3). The highest $F_{v} / F_{m}$ was reached at $0.5 \mathrm{~m}$ depth. $F_{v} / F_{m}$ decreased both in shallow waters $(0.1 \mathrm{~m})$ and at $1 \mathrm{~m}$ depth. The decrease of $F_{v} / F_{m}$ was small (less than 13\%) at maximal irradiance (at 14:30 h) at all depths except $1 \mathrm{~m}$ (a decrease of $44 \%) . F_{v} / F_{m}$ increased again in the afternoon $(17: 30 \mathrm{~h})$ reaching similar or higher values than in the morning (Fig. 3). ETR was higher in algae grown at 0.5 and $0.25 \mathrm{~m}$ than at 0.1 and $1 \mathrm{~m}$ depths (Fig. 4). Both maximal ETR and efficiency (the slope of the function ETR versus irradiance) were higher at $0.5 \mathrm{~m}$ than at $0.25 \mathrm{~m}$. No significant differences were observed in the ETR of algae grown at 0.1 and $1 \mathrm{~m}$ depth (Fig. 4). Maximal ETR was 3.25-5 times higher in algae grown at $0.25-0.5 \mathrm{~m}$ respectively than in algae growing at 0.1 and $1 \mathrm{~m}$ depths.

The concentration of phenolic compounds was much higher in algae growing at 0.5 and $0.25 \mathrm{~m}$ depth (Fig. 5) than in algae collected from 0.1 and $1 \mathrm{~m}$ depth, as was observed in the $F_{v} / F_{m}$ (Fig. 3) and ETR (Fig. 4). The 


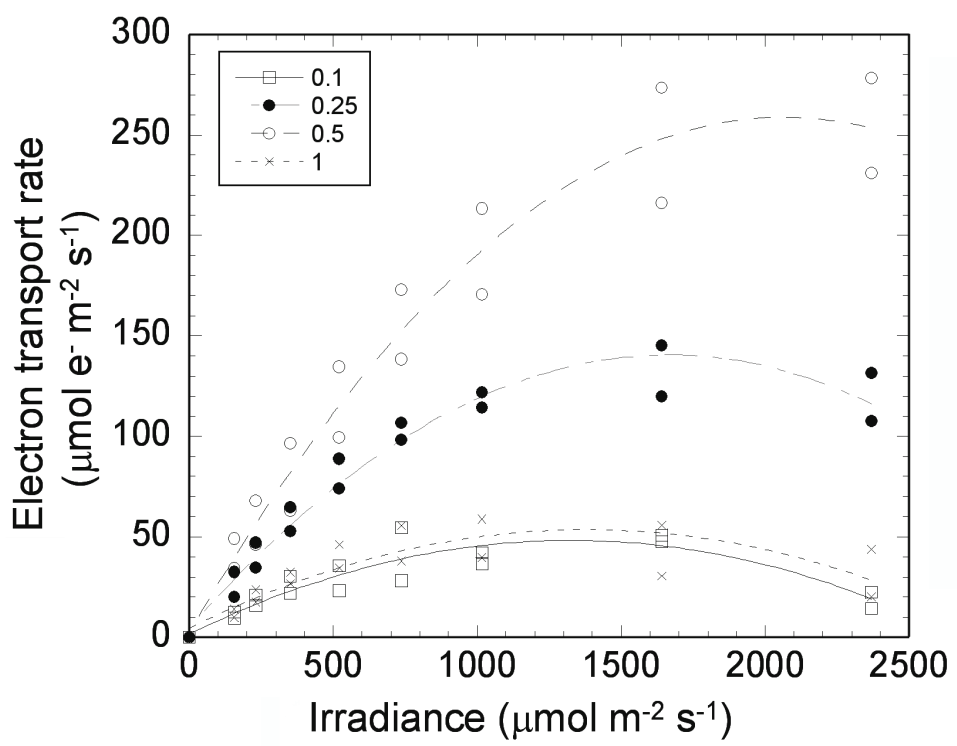

Fig. 4. Electron transport rate (expressed as $\mu \mathrm{mol}$ electrons $\mathrm{m}^{-2} \mathrm{~s}^{-1}$ ) versus irradiance curves of Zygnemopsis decussata thalli (two replicates) collected in the afternoon (17:00-18:30 h) on 17 July 2006 at different depths $(0.1,0.25,0.5 \mathrm{and} 1 \mathrm{~m})$.

phenolic concentration was about 3-5 times higher in algae collected at 0.25 and $0.5 \mathrm{~m}$ respectively than in those collected at 0.1 and $1 \mathrm{~m}$ depth.

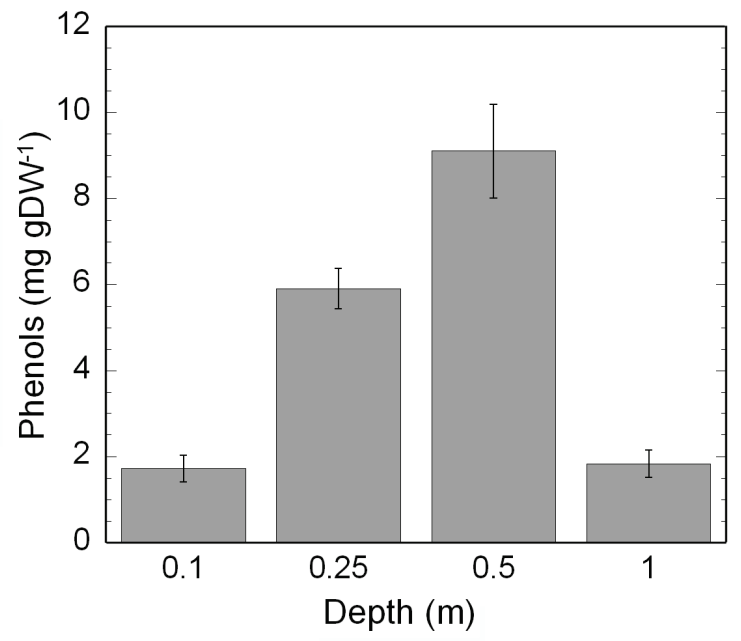

Fig. 5. Concentration of phenols expressed as $\mathrm{mg} \mathrm{g}^{-1} \mathrm{DW}$ by using phloroglucinol as standard in thalli of Zygnemopsis decussata collected in the afternoon $(18: 30 \mathrm{~h})$ on 17 July 2006. Data are expressed as mean value \pm SD $(n=6)$.

The effect of UV radiation was determined in filamentous algae grown at $0.5 \mathrm{~m}$ under three different treatments (P, PA and PAB) for 3 days (from 17 to 20 July 2006) and three times during each day (14:00, 16:00 and 18:00 h) (Fig. 6). $F_{v} / F_{m}$ values remained high from 14:00 to 18:00 $\mathrm{h}$ (about 0.68-0.7) under PAB, whereas under the $\mathrm{P}$ treatment they increased from noon (14:00 h local time or 12:00 GMT) to afternoon (18:00 $\mathrm{h}$ local time), reaching similar values as under the $\mathrm{PAB}$ treatment. The lowest values of $F_{v} / F_{m}$ were reached under the PA treatment, with a slight increase observed from noon to afternoon. $F_{v} / F_{m}$ was significantly ( $p=$ 0.045 ) higher at $14: 00 \mathrm{~h}$ under $\mathrm{PAB}$ than under the $\mathrm{P}$ and PA treatments. No significant differences were found at 16:00 $\mathrm{h}$ and 18:00 $\mathrm{h}$ between the PAB and $\mathrm{P}$ treatments. In contrast, at 18:00 h $F_{v} / F_{m}$ was significantly $(p=0.03)$ higher under $\mathrm{PAB}$ and $\mathrm{P}$ than that under the PA treatment (Fig. 6).

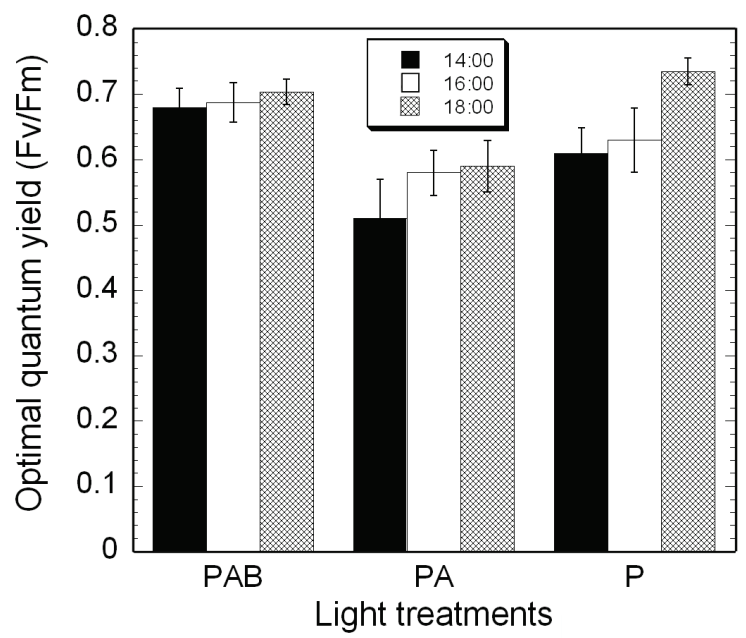

Fig. 6. Optimal quantum yield $\left(F_{v} / F_{m}\right)$ of Zygnemopsis decussata determined on 20 July 2006 at different times throughout the day $(14: 00,16: 00$ and 18:00 h) after 3 days incubation under three different light treatments: PAR+UVA+ UVB (PAB), PAR+UVA (PA) and PAR (P) by using cut-off filters. Data are expressed as mean value $\pm \mathrm{SD}(\mathrm{n}=8)$.

The combined effect of desiccation/rehydration and UV solar radiation is presented in figure 7. After 3 days' incubation (from 20 to 23 August 2007) under P, PA 
and $\mathrm{PAB}$, the algae suffered almost complete desiccation, although they kept a certain level of humidity. $F_{v} / F_{m}$ was lower in the desiccated algae than in samples collected from $0.1 \mathrm{~m}$ depth (control). $F_{v} / F_{m}$ was significantly $(p=0.04)$ higher under PAB than that under the $\mathrm{PA}$ and $\mathrm{P}$ treatments. After $1 \mathrm{~h}$ rehydration under low light irradiance (shallow conditions, about 200-300 $\mu \mathrm{mol} \mathrm{m} \mathrm{m}^{-2} \mathrm{~s}^{-1}$ solar radiation), $F_{v} / F_{m}$ increased in all treatments, whereas it remained constant in the control (submerged algae).

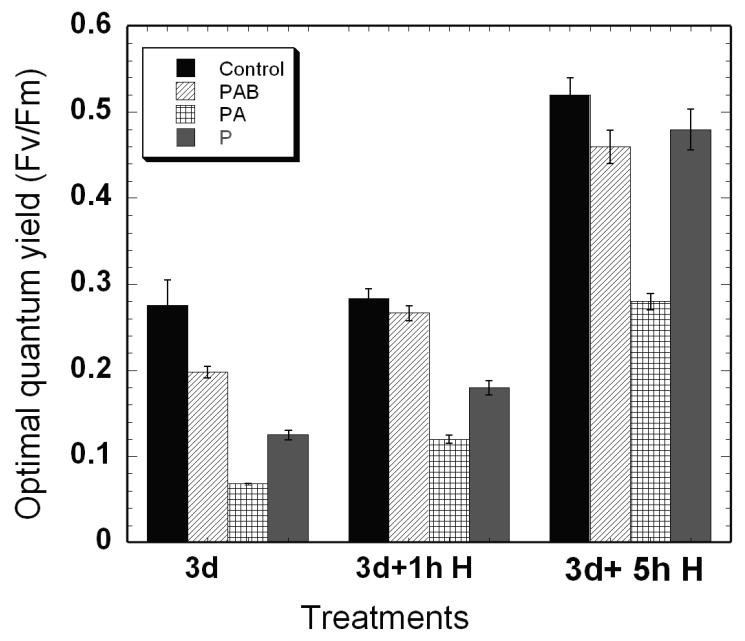

Fig. 7. Optimal quantum yield $\left(F_{v} / F_{m}\right)$ of Zygnemopsis decussata determined on 23 August 2007 after 3 days incubation under three different light treatments: PAR+UVA+UVB (PAB), PAR+UVA (PA) and PAR (P) by using cut-off filters and the control (submerged algae in shallow-water). The first measurements were conducted at 14:00 $\mathrm{h}$ with the algae partially desiccated and then hydrated for $1 \mathrm{~h}(3 \mathrm{~d}+1 \mathrm{~h} \mathrm{H})$ under low solar irradiance using neutral filters $\left(200-300 \mu \mathrm{mol} \mathrm{m} \mathrm{m}^{-2}\right.$ $\left.\mathrm{s}^{-1}\right)$ and $5 \mathrm{~h}(3 \mathrm{~d}+5 \mathrm{~h} \mathrm{H})$ at about $100-200 \mu \mathrm{mol} \mathrm{m}^{-2} \mathrm{~s}^{-1}$. Data are expressed as mean value $\pm \operatorname{SD}(n=8)$.

The increase of $F_{v} / F_{m}$ after $1 \mathrm{~h}$ rehydration compared to the initial values (3d) of the PAB-grown filamentous algae was about $40 \%$, with PA it was $100 \%$ and with $\mathrm{P}$ it was $50 \% . F_{v} / F_{m}$ in the $\mathrm{PAB}$-grown algae and control remained higher than it was under the PA and $\mathrm{P}$ treatments. $F_{v} / F_{m}$ was not significantly $(p=0.07)$ different in the control and under the PAB treatment. After $5 \mathrm{~h}$ re-hydration under low light irradiance (shallow conditions, about $100-200 \mu \mathrm{mol} \mathrm{m} \mathrm{m}^{-2} \mathrm{~s}^{-1}$ solar radiation), $F_{v} / F_{m}$ increased under all treatments as well as in the control (Fig. 7). No significant differences were found in the control compared to either PAB- or Pgrown algae, whereas $F_{v} / F_{m}$ was significantly ( $p=$ 0.035 ) higher in these treatments compared to the PA treatment. The increase of $F_{v} / F_{m}$ values after $5 \mathrm{~h}$ under rehydration under $100-200 \mu \mathrm{mol} \mathrm{m} \mathrm{m}^{-2} \mathrm{~s}^{-1}$ solar radiation compared to that under desiccation conditions (3d) was about $114 \%$ in the control, $130 \%$ under $\mathrm{PAB}, 366 \%$ under PA and 300\% in P-grown algae.

\section{DISCUSSION}

The irradiance of PAR, UVB and UVA during both sampling periods was very high, in accordance with the latitude, altitude $(3050 \mathrm{~m})$ and low dissolved organic matter content in the lake (Reche et al. 2001; Carrillo et al. 2002, 2008). The UVB/UVA and (UVA+UVB)/PAR ratios at 14:00 h local time (12:00 GMT) were higher than at sea level (Häder et al. 2001; Aguilera et al. 2004). The diffuse attenuation coefficients of the downward PAR and the three UV wavebands $(305,320$ and $380 \mathrm{~nm}$ ), both in July 2006 and August 2007, were higher than those previously reported in La Caldera lake in September 1998 (Carrillo et al. 2002) and in other high mountain lakes (Morris et al. 1995; Williamson et al. 1996; Sommaruga \& Psenner 1997). The $K_{d}$ values presented by Carrillo et al. (2008) for La Caldera lake in 2003 (UVA ranging from $0.06-032 \mathrm{~m}^{-1}$ and UVB ranging from 0.11-0.46 $\mathrm{m}^{-1}$ ) were much lower that the $K_{d}$ values presented in this paper. The explanation is that the $K_{d}$ reported by Carrillo et al. (2008) corresponded to integrated values of UVA and UVB obtained from underwater spectra determined by a spectroradiometer, and are not $K_{d}$ values of 305, 320 and $380 \mathrm{~nm}$ as they are in this study and in the values reported by Carrillo et al. (2002). In addition, the water level was lower in this study (summer 2006-2007) than in the summer of 2003 (Carrillo et al. 2008). The UV and PAR penetration is very high compared to other high mountain lakes such as Titicaca (Helbling et al. 2001), indicating that concentrations of particulate and dissolved organic material in La Caldera lake are extremely low, as has been previously reported (Reche et al. 2001; Carrillo et al. 2008).

Efficient strategies of acclimation to increased UV radiation are to be expected among both sestonic and benthic organisms growing in high mountain lakes. Carrillo et al. (2008) showed over the medium and long term the lack of harmful UVR effects on primary production, chlorophyll- $a$ and biomass, and suggested that the loss of carbon, resulting in low sestonic C:P ratios, might constitute an adaptive strategy of phytoplankton to high UVR and extreme nutrient limitation (Carrillo et al. 2008). Solar radiation causes a decrease in the optimal quantum yield in $Z$. decussata: i.e. $F_{v} / F_{m}$ was higher at $0.5 \mathrm{~m}$ depth than at 0.1 and $0.25 \mathrm{~m}$, and decreased slightly around noon, 14:30 h (12:30 GMT). The decrease of $F_{v} / F_{m}$, as an indicator of the photoinhibition effect, was in any case low (less than $10-13 \%$ at $0.1-0.5$ m). $F_{v} / F_{m}$ showed its lowest value at $1 \mathrm{~m}$ depth, in spite of the decrease in irradiance at this depth compared to $0.5 \mathrm{~m}$.

The decrease in photosynthesis was also observed as the values of electron transport rate, both maximal ETR and efficiency (the slope of ETR versus irradiance function). The highest ETR was reached in algae grown at $0.5 \mathrm{~m}\left(\right.$ as $\left.F_{v} / F_{m}\right)$ and the lowest at 0.1 and $1 \mathrm{~m}$. The low maximal ETR at $0.1 \mathrm{~m}$-grown algae (about 5 times lower than that at $0.5 \mathrm{~m}$ ) can be attributed to photoinhibition, since at $0.1 \mathrm{~m}$ there was only slight PAR 
attenuation, $3.8 \%$ compared to the air, whereas at $0.5 \mathrm{~m}$ the attenuation was $19.25 \%$. However, the decrease of maximal ETR at $1 \mathrm{~m}$ cannot be explained by an increase in irradiance or dose, since at this depth irradiance decreases (PAR attenuation of 32\% compared to surface).

Thus, both $F_{v} / F_{m}$ and ETR decreased at $1 \mathrm{~m}$ compared to $0.5 \mathrm{~m}$. The decrease in photosynthesis at $1 \mathrm{~m}$ depth could be explained by a combination of factors: decrease of PAR (low energy available), decrease of UV radiation (decreased induction of the accumulation of photoprotectors or decrease in respiration), decrease of temperature (decrease of respiration) and different nutrient availability (decreased capacity of photoprotection).

UV radiation stimulated the respiration rate of benthic algae and phytoplankton (Beardall et al. 1997; Weidman et al. 2005). Thus the decrease of UV radiation at $1 \mathrm{~m}$ could reduce gross photosynthesis. As gross photosynthesis is related to ETR (Figueroa et al. 2003), the decrease in ETR observed at $1 \mathrm{~m}$ depth could be related to the decrease in respiration rate. In the benthic algae (phytobenthos) of a clear boreal lake, photosynthesis was not affected by UV radiation but dark respiration was about $33-49 \%$ higher under $\mathrm{PAB}$ than that under the P treatment (Weidman et al. 2005); similar results were obtained in the green alga Selenastrum capricornutum (Beardall et al. 1997). In addition to UVR, respiration can also decrease with decreasing temperature; however, the difference in the temperature at 0.5 and $1 \mathrm{~m}$ depth was too small for any significant effect to be expected (approx. $0.5^{\circ} \mathrm{C}$, data not shown). Nutrient availability in algae can also be reduced due to decreasing PAR irradiance and UV radiation (Figueroa \& Viñegla 2001; Viñegla et al. 2006), but in our study the irradiance seems to be still too high to affect nutrient metabolism (at $1 \mathrm{~m}$, at noon, irradiance reached about $246 \mathrm{~W} \mathrm{~m}^{-2}$ of PAR, $26 \mathrm{~W} \mathrm{~m}^{-2}$ of UVA and $0.84 \mathrm{~W} \mathrm{~m}^{-2}$ of UVB).

The highest photosynthetic rate at $0.5 \mathrm{~m}$ can also be related to the photoprotection mechanism against UV damage, i.e. high phenolic compounds. Algae accumulate UV-absorbing compounds as a photoprotective mechanism against increased UV radiation (Häder \& Figueroa 1997), such as mycosporine-like amino acids in red algae (Bischof et al. 2006; Korbee et al. 2006; Tartarotti \& Sommaruga 2006) or phenolic compounds in brown and green algae (Pavia et al. 1997; PérezRodríguez et al. 2001; Connan et al. 2004; Han \& Han 2005; Abdala et al. 2006). Our study showed that the algae with the highest $F_{v} / F_{m}$ and ETR values (those growing at $0.5-0.25 \mathrm{~m}$ ) had a much higher content of polyphenolic compounds than those growing at 0.1 or 1 $\mathrm{m}$ depth (3-5 times at 0.25 and $0.5 \mathrm{~m}$ respectively). Precisely, maximal ETR was about 3.25-5 times higher in algae grown at 0.25 and $0.5 \mathrm{~m}$ respectively than in those at 0.1 or $1 \mathrm{~m}$ depth. Phenolic compounds can have several physiological functions; they are UV-screen sub- stances but also have antioxidant capacity (Pavia et al. 1997; Connan et al. 2004). Phenolic accumulation can be stimulated under different stress conditions, i.e. UV radiation, temperature or the action of herbivores (Pavia et al. 1997; Pérez-Rodríguez et al. 2001). Thus, the fact that the highest photosynthetic activity is in algae grown at $0.25-0.5 \mathrm{~m}$ depth could be attributed to the high content of phenolic compounds protecting the algae against environmental stress (Pavia et al. 1997).

In the second step of experiments, algae were incubated for three days under P, PA and PAB treatments in order to elucidate the role of light quality (UVR versus PAR) on photoinhibition. Surprisingly, the values of $F_{v} / F_{m}$ in algae grown at $0.5 \mathrm{~m}$ under UVB radiation (PAB treatment) were higher (except at 18:00 h) than those under only PAR (P treatment). Most studies on phytoplankton report that the greatest damage is produced by UVB radiation (Beardall et al. 1997; Villafañe et al. 2003), as in marine algae (Häder \& Figueroa 1997; Gómez \& Figueroa 1998; Bischof et al. 2006). However, other authors report beneficial effects of UVB through photoprotection of photosynthesis in algae with high solar exposure like Dictyota dichotoma, a marine brown macroalga (Flores-Moya et al. 1999) and Ulva pertusa, a green macroalga (Han \& Han 2005). Under the PA treatment (absence of UVB), the inhibitory effect was persistent in Z. decussata. Flores-Moya et al. (1999) suggested that UVA radiation exerts the main role in photoinhibition, and UVB may be involved both in the impairment and the recovery of photosynthesis. Some aquatic plants from New Zealand lakes (Hanelt et al. 2006) and shallow water algal species in marine tropical areas (Hanelt \& Roleda 2009) were even more strongly inhibited when UVB was filtered out of the simulated sun spectrum, indicating a supporting effect of UVB against photoinhibition caused by UVA radiation. The higher effect of UVA than of UVB on the decrease of primary production in La Caldera lake has also been previously reported in phytoplankton (Carrillo et al. 2002). UVB does not only cause negative effects on photosynthesis, it may even support recovery processes in algae adapted to a high UV-radiation environment in contrast to habitats with lower natural UV radiation exposure. Thus, UVB seems to have a major role in inducing and maintaining photoprotective mechanisms in high UV exposure algae, as is the case of $Z$. decussata in La Caldera lake.

Positive effects of UVB radiation were also observed in the combined experiment of UV treatments and desiccation/rehydration conducted in August 2007. $F_{v} / F_{m}$ was higher after the $3^{\text {rd }}$ exposure (reaching almost full desiccation) under PAB than under the PA and $\mathrm{P}$ treatments. Again, UVA radiation exerts the highest photoinhibitory effect. After rehydration $\left(\begin{array}{ll}1 & h\end{array}\right)$, the increase in $F_{v} / F_{m}$ was again higher under $\mathrm{PAB}$ than under the PA or P treatments. After longer hydration times $(5 \mathrm{~h}), F_{v} / F_{m}$ recovered the value of the control 
(algae growing at $0.1 \mathrm{~m}$ depth) under $\mathrm{PAB}$ and $\mathrm{P}$ treatments, remaining about $50 \%$ lower in PA than in the control. Thus, as in the experiments conducted in July 2006 , the decrease in $F_{\sqrt{ }} / F_{m}$ (in this case also under desiccation conditions) was higher in the presence of UVA, and UVB reduced its negative effect. How UVB radiation protects algae is still unknown, but it could be related to phenolic compounds. Jiang et al. (2008) showed that UV-absorbing compounds in the red alga Porphyra haitanensis increased in desiccated compared to submerged samples, and that the photochemical efficiency of PSII during exposure or the subsequent recovery process was higher in desiccated than in submerged algae (Jiang et al. 2008). Gao \& Ye 2007 reported that a critical water content (2-3\%), UVB radiation provoked a significant decrease in the effective quantum yield in colonies previously rehydrated under indoor conditions (without UVB radiation), but not in those reactivated under scattered or direct solar radiation (with UVB radiation), indicating that pre-exposure to UVB radiation during rehydration led to higher resistance to UVR during desiccation. As in the case of $Z$. decussata, UVR produced a positive effect on the protection of photosynthesis in desiccation/rehydration conditions.

The photosynthesis sensitivity of $Z$. decussata to UV radiation under both hydration and desiccation conditions indicates that this species could be a good indicator of enhanced UV radiation, as has been suggested for several aquatic bryophytes (Martínez-Abaigar et al. 2003). La Caldera lake is highly sensitive to any significant variation in the precipitation regime (Medina-Sanchez et al. 1999, Villar-Argaiz et al. 2001), and the higher fluctuation in the water volume during the recent summer periods could explain the dynamics of the epilithic communities (Sánchez-Castillo et al. 2008).

In summary, the filamentous green alga $Z$. decussata is very well acclimated to the high UV radiation reached in the high mountain lake of La Caldera $(3050 \mathrm{~m}$ altitude). High $F_{v} / F_{m}$ and ETR values are reached, also at periods of high exposure. UVB reduced the photoinhibition provoked by UVA radiation. We suggest that UVB radiation induces the accumulation of phenolic compounds (UV screen and antioxidant substances); consequently, algae with higher phenolic compounds can be expected to show greater photosynthetic activity than those with a low phenol content, due to lower stress levels (Figs 4 and 5), as Pérez-Rodríguez et al. (2001) reported in the green alga Dasycladus vermicularis. Other mechanisms contributing to recovery, such as increased respiration, as reported in phytoplankton and benthic algae (Beardall et al. 1997; Weidman et al. 2005), cannot be excluded. Further experimentation is required to elucidate the photoprotective mechanisms induced by UVB radiation.

\section{ACKNOWLEDGEMENTS}

This research was supported by the Spanish Ministries of Environment (PN2003/25) and Education and Science (CGL2005/01564, AGL2005/02655, CGL 2008/01127, CGL 2008/05407) and Consejería de Innovación, Ciencia y Empresa, Junta de Andalucía (Excelencia project P07-CVI-02598).

\section{REFERENCES}

Abdala-Díaz, R.T., A. Cabello-Pasini, E. Pérez-Rodríguez, R.M. Conde Alvárez \& F.L. Figueroa. 2006. Daily and seasonal variations of optimal quantum yield and phenolic compounds in Cystoseira tamariscifolia (Phaeophyta). Mar. Biol., 148: 459-465.

Aguilera, J., M.V. Gálvez Aranda, R. Conde, E. Pérez Rodríguez, B. Viñegla, R. Abdala, M. Segovia, E. Herrera Ceballos \& F.L. Figueroa. 2004. Series temporales de medida de radiación ultravioleta y fotosintética en Málaga. Actas Dermosifioliográficas, 95: 25-31.

Arróniz-Crespo, M., E. Nuñez-Olivera, J. Martínez-Abaigar, H. Becker, J. Sher, J. Zapp, R. Tomás \& N. Beacourt. 2006. Physiological and UV protective in the aquatic liverwort Jungermannia excertifolia Subs. cordifolia along an altitudinal gradient of UVB radiation. Funct. Plant Biol., 33: 1025-1036.

Beardall, J., T. Berman, S. Markager, R. Martínez \& V. Montecino. 1997. The effect of ultraviolet on respiration and photosynthesis in two species of microalgae. Can. J. Aquatic. Sci., 54: 687-696.

Bischof, K., I. Gómez, M. Molis, D. Hanelt, U. Karsten, U. Lüder, M.Y. Roleda, K. Zacher \& C. Wiencke. 2006. U1traviolet radiation shapes seaweed communities. Rev. Environ. Sci. Biotechnol., 5: 141-166.

Buma A.G.J., P. Boelen, W.H. Jeffrey. 2003. UVR-induced DNA damage in aquatic organisms. In: E.W. Helbling \& H.E. Zagarese (Ed.), UV effects in aquatic organisms and ecosystems. Comprehensive series in Photochemistry and Photobiology. Cambridge Royal Society of Chemistry. Cambridge: 291-327

Caldwell, M.M., J.F. Bornman, C.L. Ballaré, S.D. Flint \& G. Kulandaivelu. 2007. Terrestrial ecosystems, increased solar ultraviolet radiation, and interactions with other climate change effects. Photochem. Photobiol. Sci., 6: 252-266.

Carrillo, P., J.M. Medina-Sánchez \& M. Villar-Argaiz. 2002. The interaction of phytoplankton and bacteria in a high mountain lake: importance of the spectral composition of solar radiation. Limnol. Oceanogr., 47: 1294-1306.

Carrillo, P., J.A. Delgado-Molina, J.M. Medina-Sanchez, F.J. Bullejos. \& M. Villar-Argaiz. 2008. Phosphorus inputs unmask negative effects of ultraviolet radiation on algae in a high mountain lake. Global Change Biol., 14: 423-439.

Choo, K.S., J. Nilsson, M. Pedersén \& P. Snoeijs. 2005. Photosynthesis, carbon uptake and antioxidant defence in two coexiting filamentous green algae under different stress conditions. Mar. Ecol. Prog. Ser., 292: 127-138.

Conde-Álvarez, R.M., F.L. Figueroa, E. Bañares-España \& J.M. Nieto-Caldera. 2008. Photoprotective role of inflorescence and UV-effects on pollen viability of different freshwater plants. Aquatic Sci., 70(1): 57-64.

Connan, S., F. Goulard, V. Stiger, E. Deslandes \& E. Ar Gall. 2004. Interspecific and temporal variation in phlorotannin levels in an assemblage of brown algae. Bot. Mar., 47: 410-416.

Day, T.A. \& P.J. Neale. 2002. Effects of UVB radiation on terrestrial and aquatic primary producers. Annual Review of Ecology and Systematic, 33:371-396

Figueroa, F.L., R. Conde-Álvarez \& I. Gómez. 2003. Relations between electron transport rates determined by pulse amplitude modulated fluorescence and oxygen evolution in macroalgae under different light conditions. Photosynth. Res., 75: 259-275. 
Figueroa, F.L., S. Salles, J. Aguilera, C. Jiménez, J. Mercado, B. Viñegla, A. Flores-Moya \& M. Altamirano. 1997. Effects of solar radiation on photoinhibition and pigmentation in the red alga Porphyra leucosticta. Mar. Ecol. Prog. Ser., 151: 81-90.

Figueroa, F.L. \& B. Viñegla. 2001. Effects of solar UV radiation on photosynthesis and enzyme activities (carbonic anhydrase and nitrate reductase) in marine macroalgae from southern Spain. Rev. Chil. Hist. Nat., 74: 237-249.

Flores-Moya, A., D. Hanelt, F.L. Figueroa, M. Altamirano, B. Viñegla \& S. Salles. 1999. Involvement of solar UVB radiation in recovery of inhibited photosynthesis in the brown alga Dictyota dichotoma (Hudson) Lamoroux. $J$. Photochem. Photobiol., 49: 129-135.

Folin, O. \& V. Ciocalteu. 1927. On tyrosine and tryptophane determination in proteins. J. Biol Chem., 12: 239-243.

Franklin, L.A. \& R.M. Forster. 1997. The changing irradiance environment: consequences for marine macrophyte physiology, productivity and ecology. Eur. J. Phycol., 32: 207-232.

Gao, K. \& C. Ye. 2007. Photosynthetic insentivity of the terrestrial cyanobacterium Nostoc flagelliforme to solar UV radiation while rehydrated or desiccated. J. Phycol., 43: 628-635.

Gómez, I. \& F.L. Figueroa. 1998. Effects of solar UV stress on chlorophyll fluorescence kinetics of intertidal macroalgae from southern Spain: a case study in Gelidium species. J. Appl. Phycol., 10: 285-294.

Grzymski, J., G. Johnsen \& E. Sakshaug. 1997. The significance of intracellular self-shading on the bio-optical properties of brown, red and green macroalgae. J. Phycol., 33: 408-414.

Häder, D.-P. \& F.L. Figueroa. 1997. Annual Review: Photoecophysiology of marine macroalgae. Photochem. Photobiol., 66: 1-14.

Häder, D.P., H.D. Kumar, R.C. Smith \& R.C. Worest. 2007. Effect of solar UV radiation on aquatic ecosystems and interactions with climate change. Photochem. Photobiol. Sci., 6: 267-285.

Häder, D.-P., M. Lebert, G. Colombetti \& F.L. Figueroa. 2001. Eldonet-European light dosimeter network: 1998 data. Helgoland Mar. Res., 55: 35-44.

Han, Y.S. \& T. Han. 2005. UVB induction of UVB protection in Ulva pertusa. J. Phycol., 41: 523-530.

Hanelt, D., I. Hawes \& R. Rowena. 2006. Reduction of UVB causes an enhancement of photoinhibition in high light stressed aquatic plants from New Zealand lakes. J. Photochem. Photobiol., 84: 89-102.

Hanelt, D. \& M.Y. Roleda. 2009. UVB radiation may ameliorate photoinhibition in specific shallow-tropical marine macrophytes. Aquat. Bot., doi:10.1016.

Hessen, D.O., H.J. De Lange \& E. Van Donk. 1997. UV induced changes in phytoplankton cells and its effects on grazers. Freshwat. Biol., 38: 513-524.

Jasby, A.D. \& T. Platt. 1976. Mathematical formulation of the relationship between photosynthesis and ligh for phytoplankton. Limnol. Oceanogr., 21: 540-547.

Jiang, H., K. Gao \& E.W. Helbling. 2008. UV-absorbing compounds in Porphyra haitanenesis (Rhodophyta) with special reference to effects of desiccation. J. Appl. Phycol., 20: 387-395.

Keil, M., D.R. Jackson \& M.C. Hort. 2007. The January 2006 low ozone event over the UK 2006. Atmos. Chem. Phys., 7: 961-972.

Korbee, N., F.L. Figueroa \& J. Aguilera. 2006. Accumulation of Mycosporine-like amino acids (MAAs): biosynthesis, photocontrol and ecophysiological functions. Rev. Chil. Hist. Nat., 79: 119-32.

Leu, E., S. Falk-Petersen \& D.O. Hessen. 2007. Ultraviolet radiation negatively affects growth but not food quality of arctic diatoms. Limnol. Oceanogr., 52: 787-797.
Martínez-Abaigar, J., E. Nuñez-Olivera, N. Beacourt, M.A. García-Álvaro, R. Tomás \& M. Arróniz. 2003. Different physiological responses of two aquatic bryophytes to enhanced ultraviolet-B radiation. J. Bryol., 25: 17-30.

McKenzie, R.L., P.J. Aucamp, A.F. Bais, L.O. Björn \& M. Llyas. 2007. Changes in biologically-active ultraviolet radiation reaching the Earth's surface. Photochem. Photobiol. Sci., 6: 218-231.

Medina-Sánchez, J.M., M. Villar-Argaiz, P. Sánchez-Castillo, L. Cruz-Pizarro \& P. Carrillo. 1999. Structure changes in a planktonic food web: biotic and abiotic controls. $J$. Limnol., 58(2): 213-222.

Morris, D.P., H. Zagarese, C.E. Williamson, E. Balseira, B.R. Hargreaves, B. Modenutti, R. Moeller \& C. Queimalinos. 1995. The attenuation of solar UV radiation in lakes and the role of dissolved organic carbon. Limnol. Oceanogr., 40: 1381-1391.

Pavia, H., G. Cervin, A. Lindgren \& P. Aberg. 1997. Effects of UVB radiation and simulated herbivory on phlorotanins in the North Atlantic brown alga Ascophyllum nodosum. Mar. Ecol. Progr. Ser., 157: 139-146.

Pérez, A., I. Aguirre de Carcer \& F. Jaque. 2002. Low ozone event at Madrid in November 1996. J. Atmos. Sol. Terr. Phy., 64: 283-289.

Pérez-Rodríguez, E., J. Aguilera, I. Gómez \& F.L. Figueroa. 2001. Excretion of coumarins by the Mediterranean green alga Dasycladus vermicularis in response to environmental stress. Mar. Biol., 139: 633-639.

Reche, I., E. Pulido-Villena, J.M. Conde-Porcuna \& P. Carrillo. 2001. Photoreactivity of dissolved organic matter form high mountain lake of Sierra Nevada (Spain). Arct. Antarct. Alp. Res., 33: 426-434.

Sánchez-Castillo, P., E. Linares-Cuesta \& D. Fernández-Moreno. 2008. Changes in epilithic diatom assemblages in a Mediterranean high lake mountain (Laguna de La Caldera, Sierra Nevada, Spain) after a period of drought. J. Limnol., 67: 49-55.

Schreiber, U., T. Endo, H. Mi \& K. Asada. 1995. Quenching analysis of chlorophyll fluorescence by saturation pulse method: particular aspects relating to the study of eukaryotic algae and cyanobacteria. Plant Cell Physiol., 36: 873-882.

Shindell, D.T., D. Rind. \& P. Lonergan. 1998. Increased polar stratospheric ozone losses and delayed eventual recovery owing to increasing greenhouse-gas concentrations. Nature, 392: 589-592.

Sokal, P.R. \& F.J. Rolf. 1995. Biometry. 3rd Edition. Freeman WH, San Francisco.

Sommaruga, R. 2001. The role of solar UV radiation in the ecology of alpine lakes. J. Photochem. Photobiol., 62: 35-42.

Sommaruga, R. \& R. Psenner. 1997. Ultraviolet radiation in a high mountain lake of the Austrian Alps: air and underwater measurements. Photochem. Photobiol., 65: 957-963.

Tank, S.E., M.T. Arts \& D.W. Schindler. 2003. Direct and indirect effect of ultraviolet radiation on benthic communities: Epilithic food quality and invertebrate growth in four mountain lakes. Oikos, 103: 651-667.

Tartarotti, B. \& R. Sommaruga. 2006. Seasonal and ontogenic changes of mycosporine-like amino acids in planktonic organisms from an alpine lake. Limnol. Oceanogr., 51: 1530-1541.

Villafañe, V.E., K. Sundbäck, F.L. Figueroa \& E.W. Helbling. 2003. Photosynthesis in the aquatic environment as affected by UVR. In: E.W. Helbling \& H. Zagarese (Eds), $U V$ effects in aquatic organisms and ecosystems. The Royal Society of Chemistry, Cambridge: 357-397.

Villar-Argaiz, M., J.M. Medina-Sánchez \& P. Carrillo. 2001. Inter- and intra-annual variability in the phytoplankton community of a high mountain lake: the influence of external (atmospheric) and internal (recycled) sources of P. Freshwater Biol., 46: 1017-1034. 
Vinebrooke R.D. \& P.R. Leavitt. 1996. Effects of ultraviolet radiation on periphyton in an alpine lake. Limnol. Oceanogr. 41: 1035-1040.

Viñegla, B., M. Segovia \& F.L. Figueroa. 2006. Effect of artificial UV radiation on carbon and nitrogen metabolism in the macroalgae Fucus spiralis L. and Ulva olivascens Dangeard. Hidrobiologia, 560: 31-42.

Weidman, R.P., M.A. Turner \& L.G. Goldsborough. 2005. Limitaion on the effcets of ultraviolet radiation of benthic

Received: October 2008

Accepted: March 2009 algae in a clear boreal forest lake. J. N. Am. Benthol. Soc., 24: 820-831.

Williamson, C.E., R.S. Stemberger, D.P. Morris, T.M. Frost \& S.G. Paulsen. 1996. Ultraviolet radiation in North American lakes: attenuation estimates from DOC measurements and implication for plankton communities. Limnol. Oceanogr., 41: 1024-1034. 